\title{
Pendampingan Menu Engineering di Warung Sate Mpok Siti (H. Saih) Dalam Meningkatkan Daya Saing Usaha Kuliner
}

\section{DOI: https://doi.org/10.32509/abdimoestopo.v5i1.1829}

\author{
Tanjung Prasetyo ${ }^{1}$, Sumiyati $^{2^{*}}$
}

\author{
${ }^{1}$ Prodi Manajemen, Fakultas Ekonomi,Universitas Sahid Jakarta, \\ ${ }^{2}$ Prodi Humas, Fakultas Ilmu Komunikasi, Universitas Sahid Jakarta \\ Jalan Prof. Dr .Soepomo, Tebet Jakarta Selatan, Indonesia 12870 \\ *Email: Korespondensi: sumiyati.aprilia@gmail.com
}

\begin{abstract}
To increase the competitiveness of the culinary business, it is important to do menu engineering because with menu engineering it will be known that the cost of food is under control, a significant contribution margin, and the production volume that needs to be increased. The business stall of Mpok Siti (H. SAIH) at the Taman Anggrek Canteen, West Jakarta, offers 9 Indonesian specialties, namely various satays, various soups and soups, they have not yet engineered the menu, everything is still done based on estimates so that menu engineering guidance and assistance is needed so that business management can perform calculations on aspects of materials, production processes, and production volumes. The result is that menu engineering can also be used as an ingredient in promoting products both directly and through the media used in a way that is packaged in such a way that it is more attractive to buy and retain customers because the products purchased are guaranteed quality and at reasonable prices. The method is carried out with guidance and assistance based on data from direct observations and interviews. The analysis carried out is the Contribution Analysis of Menu Profits, Menu Popularity Levels, and Menu Classification. The results show that the owners and employees of the sate and soup stalls of Mpok Siti (H. SAIH) understand the importance of engineering menus and practicing and knowing the benefits they get clearly.
\end{abstract}

Keywords: Menu Engineering, Business Competitiveness, Culinary

\begin{abstract}
Abstrak - Untuk meningkatkan daya saing usaha kuliner penting melakukan menu engineering atau rekayasa menu karena dengan rekayasa menu akan diketahui harga pokok makanan yang terkendali, margin kontribusi yang berarti, hingga volume produksi yang perlu ditingkatkan. Warung usaha Mpok Siti (H. SAIH) di Kantin Taman Anggrek Jakarta Barat menawarkan 9 menu khas Indonesia yaitu aneka sate, aneka soto dan Sop, belum melakukan rekayasa menu, semua masih dilakukan berdasarkan perkiraan sehingga perlu bimbingan dan pendampingan menu engineering agar pengelolaan usaha dapat melakukan perhitungan aspek bahan, proses produksi, dan volume produksi. Hasilnya rekayasa menu juga dapat dijadikan bahan dalam mempromosikan produk baik langsung maumun melalui media yang digunakan dengan dikemas sedemikian rupa lebih menarik minat beli dan mempertahankan pelanggan karena produk yang dibeli terjamin kualitasnya dan dengan harga yang sewajarnya. Metode yang dilakukan dengan bimbingan dan pendampingan berdasar data hasil observasi langsung dan wawancara. Analisis yang dilakukan Analisis Kontribusi Keuntungan Menu, Tingkat Popularitas Menu, dan Klasifikasi Menu. Hasil menunjukkan bahwa pemilik dan para karyawan warung sate dan sop Mpok Siti (H. SAIH) memahami pentingnya melakukan menu engineering dan mempraktekkan serta mengetahui keuntungan yang di dapatkan dengan jelas.
\end{abstract}

Kata kunci : Menu Engineering, Daya Saing Usaha, Kuliner 


\section{PENDAHULUAN}

Usaha kuliner merupakan bisnis yang cukup menjanjikan, sehingga banyak orang yang berkecimpung di bidang ini. Daya saing usaha sangat dipengaruhi bagaimana pelaku usaha dibidang kuliner mampu mendesign menu engineering sedemikian rupa untuk miliki daya saing usaha.

Keterbatasan pengetahuan mitra tentang pentingnya rekayasa menu dalam meningkatkan daya saing menyebabkan mitra belum menyadari dampaknya bagi peningkatan laba usaha. Melalui kegiatan pengabdian kepada masyarakat (PKM) ini bemitra dengan warung usaha sate Mpok Siti ( $\mathrm{H}$. SAIH) kantin Taman Anggrek Jakarta Barat. Pra survey yang dilakukan Sate, Sop dan Soto pada kantin Taman Anggrek Jakarta Barat, dengan pengalaman usaha kuliner sejak 24 tahun pada menu khas Indonesia. Menurut Undang-Undang Nomor 20 Tahun 2008, Usaha Mikro adalah usaha produktif milik orang perorangan dan/atau badan usaha perorangan yang memenuhi kriteria Usaha Mikro sebagaimana diatur dalam Undang Undang ini. Program kemitraan bimtek pendampingan bagi mitra terkait dengan perbaikan proses bisnis melalui penerapan rekayasa menu (menu engineering) dalam meningkatkan daya saing usaha.

Menu adalah sebuah alat yang digunakan oleh usaha makanan dan minuman untuk menampilkan pruduk yang di jual dengan tujuan menarik perhatian konsumen yang berkunjung langsung pada tempat usaha atau pada media yang digunakan sebagai strategi dalam memasarkan produk dengan tujuan akhir untuk mendapat keuntungan (Tumpuan, 2021).

Menu yang ditawarkan oleh warung usaha sate Mpok Siti ( H. SAIH), merupakan produk makanan khas Indonesia yang ditawarkan kepada pelanggan. Menu khas Indonesia sering di sebut kuliner Indonesia. Rekayasa Menu makanan yang ditawarkan dalam menu jika dikelola dengan baik dapat memberikan pendapatan yang signifikan bagi mitra. Menu engineering atau rekayasa menu adalah adalah suatu metode untuk melakukan evaluasi menu dengan menyeluruh pada jangka waktu tertentu (Bagus Putu Ekadharma Susila \& Surya Nugraha, 2021).

Pendampingan dalam rekayasa menu makanan yang ditawarkan kepada pelanggan memberikan harga pokok makanan yang terkendali, margin kontribusi yang berarti, dan di sisi lain volume produksi yang tinggi jika sangat populer di kalangan pelanggan. Di sisi lain, jika pengelolaan menu tidak dilakukan dengan baik, tujuan optimalisasi pendapatan dari makanan tidak akan tercapai. Keadaan ini disebabkan karena produk makanan yang ditawarkan tidak diketahui oleh tamu dan penetapan harga pokok dan harga jual yang tidak tepat sehingga tidak memberikan margin kontribusi yang memadai. Rekayasa manajemen menu bertujuan untuk mengendalikan biaya makanan, margin kontribusi makanan yang optimal dengan menganalisis kinerja penjualan makanan. Penjualan makanan merupakan sumber utama pendapatan mitra, oleh karena itu rekayasa manajemen menu sate, sop dan soto mitra akan memaksimalkan pendapatan makanan dan meningkatkan daya saing usaha. Daya Saing usaha merupakan cara untuk memanfaatkan dan menjalankan sumber daya manusia, kemajuan informasi, aktifa, dan kemampuan untuk memperoleh nilai tambah pemasukan (Irawan, 2020). Usaha dalam hal ini adalah usaha kuliner. Kuliner menurut Kamus Bahasa Indonesia adalah berhubungan dengan masak-memasak. Masak-memasak dalam hal ini adalah memasak makanan berupa aneka sate, aneka soto dan sop.

Salah satu metode yang dapat diterapkan dalam menerapkan manajemen menu adalah pendekatan matriks, yaitu pendekatan margin kontribusi dan popularitas setiap makanan, yang biasa disebut dengan menu engineering (Wiyasha, 2014) dalam (Autoridad Nacional del Servicio Civil, 2021). Menu engineering adalah kegiatan menganalisis dan merancang strategi menu untuk memaksimalkan keuntungan.

Warung sate Mpok Siti (H.SAIH), Kantin Taman Anggrek Jakarta Barat menawarkan variasi menu yang beragam terkait Sate, Sop dan soto, Berikut adalah tabel 1 data pra survey penjualan menu tersedia : 
Tabel 1. Data Penjualan Menu Warung sate Mpok Siti (H. SAIH), Kantin Taman Anggrek Jakarta Barat

\section{Menu}

\author{
Perkiraan terjual
}

Harga

\section{Harga pokok}

Margin

Kontribusi

$\begin{array}{lc}\text { Sate ayam } & 1.200 \\ \text { Sate Kulit } & 750 \\ \text { Sate Taichan } & 935 \\ \text { Sate Kambing } & 1.125 \\ \text { Soto Ayam } & 345 \\ \text { Soto Babat } & 260 \\ \text { Soto Daging } & 310 \\ \text { Sop Iga Kambing } & 200 \\ \text { Nasi } & 456\end{array}$

Sumber: Data olahan

\section{METODE PELAKSANAN KEGIATAN}

\section{Metode kegiatan dan Teknik Pengumpulan Data}

Dalam kegiatan bimtek ini, teknik pengumpulan data sekunder menggunakan data dari Warung sate Mpok Siti (H. SAIH), Kantin Taman Anggrek Jakarta Barat yang didapatkan dengan wawancara dan survei kelapangan terlebih dahulu kemudian data tersebut diolah menggunakan analisis menu engineering dan pemberian rekomendasi untuk langkah selanjutnya bagi peningkatan daya saing usaha.

\section{Survei dan wawancara}

Permasalahan mitra yang sangat urgensi yaitu keterbatasan wawasan rekayasa menu Engineering guna meningkatkan daya saing usaha makanan khas sejenis. Keterbatasan wawasan tersebut sangat relevan terhadap produksi yang dilakukan kedepannya. 


\section{Teknik Analisa Data Mitra}

a) Analisis Kontribusi Keuntungan Menu

Rumus yang digunakan untuk menentukan kontribusi keuntungan menu adalah sebagai berikut:

$$
\begin{array}{ll}
\text { Marjin Kontribusi Item Menu } & =\text { Harga Jual }- \text { Harga Pokok } \\
\text { Total Harga Pokok } & =\text { Terjual } x \text { Harga Pokok } \\
\text { Penjualan } & =\text { Terjual } x \text { Harga Jual } \\
\text { Total Marjin Kontribusi } & =\text { Penjualan }- \text { Total Harga Pokok } \\
\text { Rata-rata Marjin Kontribusi } & =\frac{\text { Total Marjin Kontribusi }}{\text { Total Terjual }}
\end{array}
$$

b) Analisis Tingkat Popularitas Menu

Rumus yang digunakan untuk menghitung popularitas menu adalah sebagai berikut:

$$
\begin{aligned}
& \text { Indeks Popularitas }=\frac{1}{\text { Iumlah Item Menu }} \times 70 \% \\
& \text { Menu Mix\% }=\frac{\text { Terjual }}{\text { Total Terjual }} \times 100
\end{aligned}
$$

c) Analisis Klasifikasi Menu

Setiap item menu akan diklasifikasikan menjadi 4 jenis yaitu Stars, Puzzles, Plowhorses, dan Dogs

\section{Klasifikasi Item Menu}

Stars

Puzzles

Plowhorses

Dogs

*MK: Marjin Kontribusi

Sumber: (Wiyasha, 2014)

\section{Syarat yang dipenuhi}

*MK tinggi, popularitas tinggi

*MK tinggi, popularitas rendah

*MK rendah, popularitas tinggi

*MK rendah, popularitas rendah 


\section{HASIL DAN PEMBAHASAN}

Bimbingan teknis dilaksanakan di Warung sate Mpok Siti (H. SAIH), Kantin Taman Anggrek Jakarta Barat, lokasi dimana mitra melakukan aktifitas usahanya. Kegiatan pendampingan ini dihadiri langsung pihak pengelola mitra, dan tim fasilitator dalam hal melakukan pendampingan. Kegiatan pendampingan dilakukan secara berkelanjutan dalam bentuk tahapan kegiatan di bulan Desember 2021. Peningkatan daya saing usaha tidak terlepas dari kemampuan mitra dalam melakukan rekayasa menu untuk keberlanjutan usaha. Mengutip pendapat (Ninemeier, 1975) dalam (Ardiansyah \& Magdalena, 2018) yang diterjemahkan secara bebas dalam konsep bahwa industri makanan bermula dari sebuah menu.

Sumber daya manusianya (SDM) yaitu mitra diberikan pemahaman, pengertian dan pelatihan merekayasa menu sehingga SDM berkualitas mengelola bidang usaha yang digelutinya. Sebagaimana di katakan (Ardianti \& Fitranandan, n.d.) bahwa SDM penting dilatih agar lebih dapat meningkatkan produktifitas dan manajemen yaitu antara lain agar mampu mendesain produk yang khas (unik) sehingga mempunyai nilai tambah dan dapat memanajemen usaha baik dalam promosi, pengemasan maupun memasarkan. Usaha mitra adalah produk makanan sehingga pelatihan juga yang berhubungan dengan usahanya yaitu rekayasa menu atau menu engineering.

Manajemen rekayasa menu belum dilakukan mitra, karena keterbatasan wawasan dan manajemen usaha. Manajemen rekayasa menu cenderung spekulatif dan faktor kebiasaan dalam menawarkan menu, tanpa memperhatikan bagaimana menu memberikan keuntungan daya saing. Mitra diberikan bimbingan rekayasa menu agar kontribusi menu dalam hal popularitas dan profitabilitasnya menjadi tolok ukur dalam mengelola rekayasa menu yang dilakukan mitra seperti yang dipaparkan (Ninemeier, 1975) dalam (Ardiansyah \& Magdalena, 2018) dalam Planning and control for Food and beverage operation bahwa analisa manajemen rekayasa menu merupakan alat bantu pengelola mitra dalam mengetahui variasi menu yang dapat meningkatkan daya saing bagi usaha. (Dittmer, 2003) "the menu engineering worksheet is a tool that can be of great use to restauranteurs interested in maximizing profit". Diterjemahkan secara bebas bahwa menu engineering worksheet merupakan alat yang berguna untuk memaksimalkan keuntungan. Urgenitas dalam pendampingan rekayasa menu bagi mitra sangat dibutuhkan dalam peningkatan daya saing usaha kuliner khas Indonesia.

Produk usaha mitra yang dihasilkan berupa menu makanan khas Indonesia, kuliner adalah suatu bagian hidup yang erat kaitannya dengan konsumsi makanan sehari-hari karena setiap orang memerlukan makanan yang sangat dibutuhkan sehari-hari. Keanekaragaman olahan makanan rakyat melalui tradisi kuliner masyarakat menunjukkan pola-pola hidup dalam interaksi sosial, sehingga menggambarkan kearifan lokal pangan yang menginformasikan keadaan taraf atau tingkat tata kehidupan sehat, sosial, religi, dan inisiatifinisiatif lokal. Jenis makanan Indonesia memiliki arti simbolik dalam pengaruh sosial, budaya, agama, kepercayaan dan lain-lain. Sate, sop dan soto merupakan produk kuliner yang dihasilkan mitra yang memiliki citarasa khas indonesia dalam proses pengolahan produksi dan penyajiannya. Hal tersebut jika dilakukan rakayasa menu akan dapat lebih meningkatkan daya saing karena konsumen akan lebih merasa yakin dengan produk yang dibeli terjamin kualitas maupun harganya dan diharapkan dengan kata lain akan menguntungkan pihak usaha warung maupun konsumen. Jika konsumen merasa puas pada umumnya akan terus menjadi langganan dan menginformasikan serta merekomendasikan pada orang-orang dilingkunnya 
atau rekan-rekannya.

Dengan bimbingan dan pendampingan menu engineering atau rekayasa menu maka Produk Warung Mpok Siti (H. SAIH) dalam pemrosesan produk menu yang ditawarkan sudah relatif sangat baik dari proses pemilihan daging sebagai bahan dasar menu, cara penyimpanan. Urgenitas pendampingan dalam proses produksi berkenaan, Cara pemotongan bahan baku olahan sate yang belum terstandarisasi dalam potongan dan ukuran yang memiliki kesesuaian satu dengan yang lain yang miliki potensi kehilangan daya saing usaha dari segi nilai produk dan biaya produksi yang dihasilkan tidak kompetitif, Berikutnya hal yang menjadi perhatian dalam kualitas bahan baku sumber daya air kurang baik guna keterjaminan rasa dan kebersihan pengolahan produk, Penyimpanan bahan baku sudah sangat baik dengan ketersediaan lemari pendingin sebelum bahan baku dilakukan pemrosesan dalam memenuhi variasi menu yang ditawarkan, namun catatan diberikan pada cara menyimpan bahan baku dan Penggunaan alat pendukung proses produksi juga sangat mempengaruhi kecepatan dalam proses produksi dan penyajian.

Merujuk beberapa aspek produksi yang diketahui masih miliki keterbatasan dan perbaikan, maka dalam bimtek pun memberikan rekomendasi aksi yang dapat dilakukan oleh mitra dan solusi dalam mendukung rekayasa menu yang diterapkan diantaranya dengan pengadaan alat dan tata cara proses produksi bagi usaha mitra. Usaha mitra yang masih mempertahankan manajemen kekerabatan, dapat menjadi nilai tambah dan juga kekurangan salah satu diantaranya konsistensi kualitas citarasa dan langganan yang dimiliki.

Terlepas hal tersebut usaha mitra cendrung stagnan dalam layanan karena keterbatasan wawasan rekayasa menu yang tidak dipahami dan cendrung hanya melakukan kebiasaan dalam penyediaan variasi menu. Berkenaan hal tersebut disini sangat penting membangun komunikasi kerabat pemilik dan karyawan warung serta konsumen yang efektif sebagai kunci utama yang dapat mendukung penerapan rekayasa menu pada usaha mitra agar berkelanjutan. Komunikasi dikatakan efektif jika penerima pesan mempunyai persepsi sama terhadap pesan yang disampaikan dari pemberi pesan. Dalam hal ini diharapkan persepsi lebih yaitu bahwa rekayasa menu penting dilakukan. Komunikasi dalam memberikan pengetahuan pada karyawan dan memberikan pelayanan.

Pada konsumen dalam bentuk komunikasi interpersonal. Komunikasi interpersonal Komunikasi interpersonal yaitu kumunikasi yang dilakukan secara langsung bertatap muka antara pengirim dan penerima pesan sehingga saling menagkap reaksi kedua belah pihak yang berkomunikasi (Irfal, 2021). Dalam hal ini komunmikasi dilakukan oleh pemilik warung kepada karyawan dan dapat juga dari pemilik warung maupun karyawan pada konsumen yang membeli secara langsung produk yang dijual. Kelebihan komunikasi secara langsung ini adalah masing-masing pihak baik pemilik atau karyawan dan pembeli langsung mengetahu seperti jelas tidaknya apa yang dibicarakan atau melihat langsung reaksi konsumen pada saat diberikan layanan. Agar komunikasi interpersonal efektif yang perlu dipertimbangkan adalah keterbukaan, empati (sikap mendukung), sikap positif, dan (4) kesetaraan (Devito, 2011). Berkaitan dengan hal tersebut keterbukaan pengusaha warung baik pada pada karyawan maupun pembeli dalam memberikan pesan atau informasi, bersedia menanggapi masukan-masukan yang diberikan dan memberikan jawaban secara jujur. Disamping itu pengusaha warung juga harus berempati terhadap karyawan maupun konsumen akan kebutuhan baik berupa perhatian maupun yang diinginkan. Sikap positif juga penting baik dalam menerima kritikan atau masukan yang diberika agar terjadi interaksi yang lebih baik. Selanjutnya perlunya menunjukkan sikap kesetaraan dengan memperlakukan baik pada karyawan maupun pembeli berusaha tidak membeda-bedakan. Komunikasi dapat efektif terjadi juga jika kedua belah pihak juga melakukan hal yang sama.

Dari kegiatan pendampingan bimtek mitra, menjadi sangat jelas terkait urgensi rekayasa 
menu mitra dalam peningkatan daya saing usaha kuliner khas Indonesia juga tidak terlepas dari masalah komunikasi sebagai alat untuk aksi, interaksi maupun transaksi dalam hubungan dengan karyawan maupun konsumen.

Tabel 2. Kontribusi Keuntungan Mitra

\begin{tabular}{|c|c|c|c|c|c|c|c|c|c|c|c|}
\hline No & $\begin{array}{c}\text { Nama Item } \\
\text { Menu (l) }\end{array}$ & $\begin{array}{l}\text { Teriual } \\
\text { (2) }\end{array}$ & $\%$ & $\begin{array}{c}\text { HPM } \\
(4)\end{array}$ & $\begin{array}{l}\mathrm{HJ} \\
(5)\end{array}$ & $\begin{array}{l}\text { MK } \\
(6)\end{array}$ & $\begin{array}{l}\text { Tpen } \\
\text { (7) }\end{array}$ & $\begin{array}{c}\text { TMK } \\
(8)\end{array}$ & $\begin{array}{c}\text { KMK } \\
(9)\end{array}$ & $\begin{array}{c}\text { KBM } \\
(10)\end{array}$ & $\begin{array}{l}\mathrm{KM} \\
\text { (1l) }\end{array}$ \\
\hline 1 & Sate Avam & 1200 & 21 & 12000 & 17000 & 5000 & 20400000 & 6000000 & $\mathrm{H}$ & $\mathrm{H}^{\prime}$ & Star \\
\hline 2 & Sate Kulit & 750 & 13 & 13000 & 15000 & 2000 & 11250000 & 1500000 & $\mathrm{~L}$ & $\mathrm{H}$ & Plowhorses \\
\hline 3 & Sate Taichan & 935 & 17 & 12000 & 17000 & 5000 & 15895000 & 4675000 & $\mathrm{H}$ & $\mathrm{H}$ & Star \\
\hline 4 & $\begin{array}{c}\text { Sate } \\
\text { Kambing }\end{array}$ & 1125 & 20 & 20000 & 25000 & 5000 & 28125000 & 5625000 & $\mathrm{H}$ & $\mathrm{H}$ & Star \\
\hline 5 & Soto Avam & 345 & 6 & 7000 & 10000 & 3000 & 3450000 & 1035000 & L & $\mathrm{L}$ & Dogs \\
\hline 6 & Soto Babat & 260 & 5 & 8000 & 10000 & 2000 & 2600000 & 520000 & L & $\mathrm{L}$ & Dogs \\
\hline 7 & Soto Daging & 310 & 6 & 12000 & 15000 & 3000 & 4650000 & 930000 & L & $\mathrm{L}$ & Dogs \\
\hline 8 & $\begin{array}{l}\text { Sop Iga } \\
\text { Kambing }\end{array}$ & 200 & 4 & 20000 & 22000 & 2000 & 4400000 & 400000 & L & $\mathrm{L}$ & Dogs \\
\hline 9 & $\begin{array}{l}\text { Nasi } \\
\text { Total }\end{array}$ & $\begin{array}{c}456 \\
5581\end{array}$ & 8 & 3000 & 5000 & 2000 & 2280000 & $\begin{array}{c}912000 \\
21597000\end{array}$ & L & $\mathrm{H}$ & Plowhorses \\
\hline & & & & \multicolumn{2}{|c|}{$\begin{array}{l}\text { Rata - Rata MK } \\
\text { Tingkat Popularitas }\end{array}$} & & & $\begin{array}{c}3,870 \\
434,078\end{array}$ & & & \\
\hline
\end{tabular}

Merujuk data olahan prasurvey pada tabel 1.untuk memahami lebih dalam kontribusi keuntungan menu mitra yang terbaik dengan metode pendekatan matrix yang telah diolah untuk memahami kontribusi margin dan tingkat popularitas dari mitra berikut adalah hasil analisis rekayasa menu pada mitra dilihat pada tabel 2 :

Tabel 3. Margin Kontribusi

\begin{tabular}{cl} 
Kategori & \multicolumn{2}{l}{ Menu Makanan } \\
Stars & 1. Sate Ayam \\
& 2. Sate Taichan \\
& 3. Sate Kambing \\
\hline Puzzles & \multicolumn{1}{c}{-} \\
Plowhorses & 1. Sate Kulit \\
& 2. Nasi \\
\hline Dogs & 1. Soto Ayam \\
& 2. Soto Babat \\
& 3. Soto Daging \\
& 4. Sop Iga Kambing
\end{tabular}

Saat kegiatan ini berlangsung, mitra pengelola masih melakukan semua variasi menu yang ada notabene tradisi atau faktor kebiasaan yang dilakukan selama melakukan usaha. Mitra pengelola dapat memperhatikan lebih lanjut hasil rekayasa menu yang diolah secara sederhana untuk diimplementasikan kedepannya dengan merujuk tabel 2 sebagai data olahan analisa rekayasa menu mitra pada periode 2021.

Maka dapat menjadi perhatian khusus pada penawaran produk sate merupakan produk menu andalan bagi usaha mitra disebabkan memang mitra usaha konsisten dalam melakukan 
penawaran menu tersebut. Terlihat dalam olahan rekayasa menu mix, sate dapat dikategorikan ke dalam menu Stars dimana hampir keseluruhan memberikan kontribusi margin yang tinggi bagi mitra dan juga cukup dikenal sebagai menu utama mitra oleh pelanggan. Berkenaan menu sate terkonfirmasi oleh pihak mitra pengelola ditawarkan semua setiap harinya tanpa memperhatikan bagaimana menu sate dan varian sate mana yang memberikan kontribusi terbaik. Pendampingan yang diberikan diantaranya meningkatkan kualitas produk khususnya standarisasi potongan daging sate yang terukur dalam satuan gram yang sama dengan menggunakan alat bantu dan teknik potong yang terstandarisasi tanpa hilangkan citarasa produk. Ketergantungan olahan yang berbahan dasar daging, sangat dipengaruhi ketersediaan bahan baku di pasar sehingga potensi resiko yang akan mempengaruhi daya saing produk, tindaklanjut preventif ketidaktersediaan bahan baku yang memiliki sensitifitas terhadap harga beli tetap diperhatikan.

Berkenaan menu sate kulit dan nasi yang termasuk kedalam kategori Plowhorse, mitra diharapkan dapat lebih bijaksana dalam melakukan penawaran menu ini, karena menu ini termasuk dalam dalam menu yang memberikan margin kontribusi yang rendah namun menu ini sangat diminati oleh konsumen yang ada. Ketersedian menu ini, dianggap untuk memenuhi trend/ kebutuhan sesaat sebagai pilihan yang sewaktu dapat dihilangkan. Pendampingan yang dapat diberikan bagi mitra berkenaan sate kulit dan nasi diataranya perhatikan penjualan perhari terkait permintaan menu sate kulit dan nasi tidak tertutup kemungkinan dapat dilakukan bundling menu varian agar dapat meningkatkan margin bagi produk ini. Sate kulit diharapkan dapat meningkat dalam kategori Stars, namun saat ini di harapkam mitra pengelola terus meningkatkan kualitas produk dengan menyesuaikan kebutuhan pasar.

Variasi menu yang lainnya seperti soto dan sop menjadi menu yang berkategori Dogs, perlakuan berkenaan varian produk ini dapat dipahami memiliki margin kontribusi rendah dengan tingkat popularitas yang rendah jelas terlihat dalam tabel 2. Pendampingan yang dapat dilakukan berkenaan menu yang berkategori ini kepada mitra idealnya adalah menghapus menu tersebut dalam list ataupun memilih varian menu soto dan sop sebagai pilihan menu. Pertimbangan bahan baku yang sejenis berupa olahan daging ayam dan kambing maka tetap ditawarkan dengan modifikasi nama varian menu dan tehnik penyajian agar lebih menarik bagi konsumen untuk mencobanya dengan pertimbngan pelaku usaha menu sejenis lainnya.

\section{SIMPULAN}

Dari hasil Pendampingan Bimtek di warung usaha sate dan sop Mpok Siti (H. SAIH) kantin Taman Anggrek Jakarta Barat, keberlanjutan dan konsistensi dalam penerapan standarisasi aspek produk dalam proses produksi oleh mitra yang terakslerasi dengan baik dapat mendukung rekayasa menu yang diterapkan berdasarkan kategorisasi menu dengan tata cara proses produksi yang benar sehingga menu yang dihasilkan semakin berkualitas dan memiliki daya saing, penerapan kategorisasi Menu mix melalui margin kontribusi dan popularitas menu dengan hasil menu sate adalah menu unggulan dari usaha mitra dibandingkan beberapa varian menu lainnya sebagai pelengkap ketersediaan, penting bagi mitra. Berkenaan menu unggulan diharapkan keberlanjutan penerapan peningkatan standarisasi produk yang terukur dalam proses pengolahan dan untuk menu varian pelengkap ketersediaan tetap menjaga kualitas dan keterbutuhan pasar dengan melakukan modifikasi nama varian dan penyajian sehingga daya saing usaha mitra tetap terjaga dan meningkat, rekomendasi aksi merupakan lanjutan dalam pendampingan yang berdasarkan hasil rekayasa menu yang dilakukan usaha mitra memiliki 3 kategori menu. Rekomendasi aksi kategori stars lakukan secara keberlanjutan dalam peningkatan standarisasi kualitas 
produk serta tindakan prefentif dalam ketersediaan bahan baku yang sensitif terhadap haraga dan stok di pasaran, untuk kategori plowhorse perhatikan trend permintaan pelanggan dan ketersediaannya hanya seperti pelengkap saja dan teteap perhatikan standart kualitas produk dan permintaan pasar, untuk kategori Dogs direkomendasikan jika ingin dipertahankan lakukan modifikasi nama varian menu dan tehnik penyajian.

\section{DAFTAR PUSTAKA}

Ardiansyah, I., \& Magdalena, V. (2018). Strategi Pengembangan Bisnis Berbasis Menu Engineering Di Kambing Soon Resto and Cafe Bandung. Journal FAME: Journal Food and Beverage, Product and Services, Accomodation Industry, Entertainment Services, 1(1). https://doi.org/10.30813/fame.v1i1.1326

Ardianti, D., \& Fitranandan, C. A. (n.d.). Program Kemitraan Masyarakat ( PKM ) untuk Usaha Sabun Herbal di Kota Bandung. 23-29.

Bagus Putu Ekadharma Susila, \& Surya Nugraha. (2021). Menu Engineering Sebagai Strategi Penetapan Produk Makanan Dalam Menghadapi Tatanan Kehidupan Baru Di Kori Restaurant \& Bar Kuta - Bali. Journal of Applied Management and Accounting Science, 3(1), 14-27. https://doi.org/10.51713/jamas.v3i1.45

Devito, J. A. (2011). Komunikasi Antarmanusia. Komunikasi Antarmanusia. Kuliah Dasar, 479-488.

Dittmer, P. R. (2003). Principles of food, beverage, and labor cost controls (7th ed.). John Wiley \& Sons, Inc., New York.

Irawan, D. (2020). Peningkatan Daya Saing Usaha Micro Kecil dan Menengah Melalui Jaringan Usaha. Coopetition: Jurnal Ilmiah Manajemen, XI(2), 103-116. https://www.neliti.com/id/publications/325683/

Irfal. (2021). View of Pengaruh Komunikasi Interpersonal Terhadap Kinerja Resepsionis di Qunci Villas Hotel, Lombok - NTB. Jurnal Manajemen Dan Akuntansi, 16, 76-84. https://ojs3.umc.ac.id/index.php/VL/article/view/1668/1164

Ninemeier, J. D. (1975). Product profile. Computer, 8(6), 78. https://doi.org/10.1109/CM.1975.219003

Tumpuan, A. (2021). Penerapan Sistem Menu Engineering Dalam Upaya Peningkatan Kualitas Menu di Restoran Bintan Inti Executive Village Clubhouse. Jurnal Pariwisata Terapan, 5(1), 60. https://doi.org/10.22146/jpt.66724

Wiyasha, I. (2014). Akuntansi Manajemen untuk Hotel dan Restoran (F. Sigit Suryantoro (ed.); 2nd ed.). C.V ANDI OFFSET.

Yana Diana, S.E., M. S. (2021). Analisis Foods And Beverages Costing Dengan Pendekatan Matriks Kaitannya Dengan Strategi Pemasaran Pada Olla Restoran Hotel Granada Johor Bahru Malaysia. Angewandte Chemie International Edition, 6(11), 951-952., 7(1), 2013-2015. 